\title{
ANÁLISE DA TAXA DE INFILTRAÇÃO DENTÁRIA E AÇÃO ANTIMICROBIANA DE MATERIAIS RESTAURADORES PROVISÓRIOS
}

Amanda MUSHASHE, Joslei BOHN, Rodrigo RAZZOTO, Simone OLIVEIRA, Paulo TOMAZINHO

O objetivo deste trabalho foi verificar o vedamento marginal e ação antimicrobiana de seis materiais restauradores provisórios disponíveis no mercado. Verificou-se a ação antimicrobiana dos cimentos, por meio da análise dos halos de inibição promovidos por 60 corpos-de-prova em placas de Pétri incubadas com Staphylococcus aureus, sendo que 30 amostras tomaram presa previamente, fora da placa de cultura, e 30 no próprio meio. Observou-se ainda a capacidade de selamento marginal em 60 incisivos bovinos, devidamente preparados. Após terem sido submetidos à imersão por 24 horas em solução de azul de metileno a $0,5 \%$, foram seccionados longitudinalmente para verificar a taxa de microinfiltração marginal. $\mathrm{Na}$ análise da ação antimicrobiana, verificou-se que houve diferença significativa entre os cimentos endurecidos antes e após a colocação nas placas de cultura (significância $5 \%$ ). O material Coltoso/® foi o que apresentou maior halo de inibição, enquanto o Villevie® teve os piores resultados. Quanto à microinfiltração marginal, nenhum dos materiais permitiu a penetração da solução de azul de metileno entre a estrutura dentária e o próprio cimento. Conclui-se que o vedamento marginal observado nos cimentos foi satisfatório. Entretanto, a ação antimicrobiana foi insatisfatória, sendo os halos de inibição relativamente pequenos.

Palavras-chave: produtos com ação antimicrobiana; cimentos dentários; infiltração dentária 